\title{
ДИАЛОГИЧЕСКАЯ ПРИРОДА ОБЩЕСТВЕННОГО ИДЕАЛА
}

\section{В.Ю. Даренский}

Понятие «общественный идеал» в современной философской и гуманитарной мысли является малоупотребительным и фактически приобрело статус анахронизма. Чаще всего оно употребляется в историко-философских исследованиях, в частности, наследия П.И. Новгородцева, посвятившего разработке этого понятия свою главную книгу (а по сути, тема общественного идеала является центральной во всем его творчестве) ${ }^{1}$. Вместе с тем, обращение к этой работе П.И. Новгородцева в наше время может иметь по настоящему продуктивный и творческий характер только в том случае, если оно происходит в контексте встречного поиска, в рамках построения самостоятельных концепций общественного идеала современными авторами, с использованием понятийного инструментария, наработанного в философии XX века. С другой стороны, современные подходы должны основываться и на опыте критического переосмысления западноевропейских общественных идеалов, предпринятом в названном произведении русского философа.

В последнее время наблюдается актуализация понятия «общественный идеал» для осмысления как современной социально-философской проблематики, так и историософских проблем. Первый аспект отражен в работах А.Гарника, С. Максимова, О.Помникова, В. Снегирева ${ }^{2}$; по-

\footnotetext{
${ }^{1}$ Новгородиев П.И. Об общественном идеале. - М.: Пресса, 1991.

${ }^{2}$ См.: Гарник А. Учение П.И.Новгородцева об общественном идеале в контексте проблемы дисциплинарной идентификации современной отечественной философии права // Ідея правової держави: історія і сучасність.: Зб. наук. праць, присвячений 135-річчю П.І. Новгородцева. - Київ-Луганськ: РВВ ЛАВС, 2002. - С. 42-57.; Maкcuмов C. К проблеме общественного идеала: правовое государство или правовое общество? // Вісник ЛАВС ім. 10-річчя незалежності України. Спец. випуск. - Ч. І. 2004. - С. 30-38.; Помников О. П.И. Новгородцев о нравственном значении общественного прогресса // Там же.- Ч. II. - 2004.- C.83-95.; Снегирев В. Общественный иде-
} 
следний - в статьях С. Бойчука и И. Яценко ${ }^{3}$. В новейших зарубежных публикациях следует отметить концепцию В.Федотовой, обосновывающую «постмодернизацию» как общественный идеал современного глобального мира, состоящий в возможном синтезе культурного традиционализма с новейшими технологиями (в том числе природоохранными и гуманитарными $)^{4}$. Такой подход в целом может быть понят в русле идеи П.И. Новгородцева о «восстановлении святынь» как основе общественного идеала. Представляют интерес также и некоторые концепции общественного идеала, развивавшиеся в советский период и несущие в себе элементы, близкие идеям П.И. Новгородцева. Это касается, в частности, работ Э. Ильенкова, В. Давидовича и особенно М. Мамардашвили.

Э. Ильенковым высказаны достаточно провокативные соображения о природе общественного идеала и его отношения к текущей действительности, сохраняющие свою эвристическую ценность. В частности, к ним относятся следующие его определения общественного идеала: «Это ни в коем случае не нравственный или интеллектуальный образ желаемого, но не реального состояния, не императив, который противостоит эмпирической действительности и условиям места и времени, как что-то вне их и против них стоящее. Это-сама действительность в полном теоретическом синтезе ее имманентных противоречий, т.е. с точки зрения тех перспектив, которые ей же самой имманентны. .. Деятельность индивида... всегда «отклоняется» от абстрактно-всеобщего теоретического норматива. Но это отклонение и есть единственно возможная форма и способ реализации всеобщего идеала, это и есть сам идеал, скорректированный условиями места и времени, характером материала, в котором он осуществляется, особенностями личности индивидуума и т.д. То же самое относится и к реализации идеала в специфических национальных условиях... В этом в полной мере сказывается диалектика всеобщего, особенного и индивидуального» ${ }^{5}$. Хотя Э. Ильенков, в силу своей мировоззренческой ориентированности, упускает из виду идеал как трансценденцию наличного бытия в его актуальной полноте (а тем самым, и ее ущербности), но акцентирование им имманентности идеала само по себе продуктивно, поскольку приводит к осмыслению неравенства наличного социального бытия самому себе, его потенциальной и актуальной открытости высшим качествам и состояниям (т.е. диалектически, хотя и неявно, полагает уже

ал П.И. Новгородцева и попытка его реализации // Там же. - Ч. II. - 2004. - C. 75-83.

${ }^{3} \mathrm{C}$ м.: Бойчук C. Аристократический идеал в истории европейской цивилизации // Там же.- Ч.ІІ. - 2004.-C.138-147.; Ященко И. Общественный идеал современных цивилизаций // Ідея правової держави: історія і сучасність. - С. 213-218.

${ }^{4}$ См.: Федотова В.Г. Типология модернизаций и способов их изучения // Вопросы философии. - 2000. - №4. - С. 24-27.

${ }^{5}$ Илъенков Э.В. Идеал // Ильенков Э.В. Философия и культура.-М.: Политиздат, 1991. - C. $210,212$. 
трансцендентность идеала).

В. Давидович, развивая деятельностный подход к пониманию природы социального идеала, определял его через категорию справедливости, а последнюю, в свою очередь, понимал иерархически: помимо социально-экономического и формально-юридического аспектов справедливости он концентрировал внимание на нравственном содержании этого понятия как онтологически высшем и необъяснимом только на основании двух первых (а иногда и противоречащем им). Это содержание определялось им как «,несимметричность“" в подлинно нравственных отношениях», всегда включающих в себя «оказание помощи, благодеяние, заботу, поддержку без расчета на адекватный „ответ“» ${ }^{6}$ Это личностно-нравственное содержание понятия справедливости, вьходящее за рамки только социального ее смысла, по сути, представляет собой инвариантный критерий реализованности общественного идеала в любых конкретно-исторических условиях.

М. Мамардашвили предложил понимание общественного идеала с точки зрения определенных онтологических структур культуры и социальности в целом, обеспечивающих сущностную самореализацию человека. Такими структурами, по М. Мамардашвили, являются, во-первых, символические образования, «кристаллизации» важнейших элементов человеческого опыта, а во-вторых, делтельностные образиы поступков, в которых происходит как реализация личностного бытия человека, так и формирование социальной среды- включение в нее соответствующих идеалов «поступающего» поведения, в той или иной степени приобретающих нормативно-императивный характер. Наличие таких структур и их реализованность в индивидуальном и социальном бытии М.Мамардашвили называет «взрослым состоянием» общества, на индивидуальном уровне выражающемся в «способности (или культуре) практикуемой сложно$c m u{ }^{7}$. Все это также можно рассматривать в качестве инвариантных (общеисторических) критериев реализованности общественного идеала.

Кратко рассмотренные подходы очерчивают современный контекст философского понимания природы общественного идеала. Целью данной статьи является исследование онтологических аспектов общественного идеала, на основании которых углубляется понимание его отличия от социальных утопий и критериев его воплощенности в конкретно-исторических условиях. В рамках этой цели предполагается решение трех задач: 1) построение общей типологии представлений об общественном идеале; 2) выделение диалогизма как одного из инвариантных признаков об-

\footnotetext{
${ }^{6}$ Давидович B.E. Социальная справедливость: идеал и принцип деятельности. - М.: Политиздат, 1991. - С. 204.

${ }^{7}$ Мамардашвили М.К. Если осмелиться быть... (Интервью) // Мамардашвили М.К. Как я понимаю философию.-М.: Прогресс, 1990.- С. 174.
} 
щественного идеала; 3) анализ философско-антропологических аспектов концепции общественного идеала П.И. Новгородцева, конгениальных традиции «философии диалога» $\mathrm{XX}$ века.

Помимо названных выше теоретических подходов следует выделить и ряд конкретно-исторических типов представлений об общественном идеале в рамках массового сознания. Первый, свойственный архаическим и традиционным цивилизациям, может быть определен как космоморфный в том смысле, что здесь идеальное устройство общества мыслится как часть и следствие изначальной упорядоченности Мира, управляемого единым и вечным Законом (в язычестве- роком, в христианстве-божественным Провидением). Тот факт, что именно человеческое бытие (как индивидуальное, так и коллективное) может «выпадать» из этого высшего Порядка и даже сознательно бороться с ним, понимается не как его нарушение, но как его же специфическое проявление, неизбежно влекущее за собой соответствующее возмездие: «Ибо знает Господь путь праведных, а путь нечестивых погибнет» (Пс.1.6). Тем самым, человеческая свобода и способность самоопределения личности не только не противоречат существованию вселенского Порядка, но и были бы невозможны без онтологической укорененности в нем. Вместе с тем, из таких представлений с очевидностью следует и однозначное понимание сущности общественного идеала. Это идеал всеобщей праведности, которая, естественно, по-разному понимается в язычестве и христианстве, но тем не менее в обоих случаях имеет место именно космоморфный тип представлений о социальном идеале, который в христианстве становится намного более содержательным (теоцентрическим). В соответствии с этим общим принципом, общество тем ближе к своему идеалу, чем меньше в нем нарушений вселенского порядка и божественной Воли на уровне человеческой деятельности. Праведность - это состояние, когда такие нарушения или отсутствуют или, если это невозможно (например, в состоянии войны), сведены к минимуму. Такой тип общественного идеала обычно именуется «консервативным», что в принципе верно, если отдавать себе отчет в том, что именно здесь сохраняется и «консервируется», а именно - вечный, сакральный, божественный порядок вещей и дел человеческих, нарушение которого понимается как преступление не только в нравственном или юридическом, но и в онтологическом смысле.

Радикально иной тип представлений об общественном идеале формируется в сознании человека Нового и Новейшего времени, неизбежно эволюционизирующем от христианского гуманизма к революционному антропоцентризму, и, далее, к эгоцентрическому нигилизму и полному разложению. Уже в рамках христианского гуманизма (эпоха Возрождения) начинается расщепление традиционного (космоморфного) типа общественного идеала в двух направлениях: к проектам гедонистического 
земного устроения (возникновение «утопий», начиная с Т. Мора и Т. Кампанеллы), и к проектам радикальной секуляризации социальной жизни (Н. Макиавелли и т.д.). Далее, на стадии «революционного сознания», формирующегося в эпоху Просвещения и Французской революции, антропоцентрическое мироотношение выражается в форме стремления к радикальному преобразованию мира (как социального, так и природного). Революционные утопии выступают в трех формах: более «мягкой»социалистической, более «радикальной»- анархической , а также коммунистической, «синтезирующей» в себе элементы обеих и в силу этого более привлекательной для опустошенного сознания безрелигиозной эпохи.

Исследование П.И. Новгородцева «Об общественном идеале» возникает в ситуации кризиса революционных утопий в общественном сознании Западной Европы и в кульминационный момент их катастрофического вторжения в Россию. Однако эта работа идет значительно далее простой критики революционного сознания, столь же критически относясь и к идеологиям, которые ему противостоят. Философское «зерно», из которого произрастает вся концепция П.И.Новгородцева, состоит в понимании принципиальной неустранимости утопического элемента в любых секулярных идеологиях - как революционных, так и либеральных. Но это, в свою очередь, отнюдь не противоречит их прагматической ценности на определенных этапах развития общества. Об этом сам П.И. Новгородцев пишет следующим образом: «Крушение веры в совершенное правовое государство есть только крушение утопии, с отпадением которой остается, однако, в полной силе настоящее историческое призвание правового государства в его практических стремлениях и реальных достижениях. Но точно так же и крушение утопий социализма и анархизма нисколько не колеблет тех жизненных начал, которые, бесспорно, заключаются в этих учениях и которые каждое беспристрастное исследование должно в них признать» ${ }^{8}$.

Неустранимость утопического элемента во всех без исключения секулярных идеологиях объясняется общим основанием как либерального, так и революционного сознания - стремлением к земному устроению, совершенно автономному от каких-либо религиозных оснований. Всегда неизбежное «крушение утопий земного рая» (П.И. Новгородцев) объясняется, таким образом, причинами отнюдь не эмпирического характера, на которые по наивности ссылаются как революционеры, так и либералы. «Неготовность» народных масс, сопротивление «врагов», недостатки самих теорий и т.п.-суть причины вторичного порядка, которые в конечном счете были бы легко преодолимы, если бы за ними не стояла при-

${ }^{8}$ Новгородцев П.И. Об общественном идеале.-М.: Пресса, 1991.-С.17. 
чина более фундаментального, онтологического характера. В основе секулярных идеологий «земного устроения без Бога» (Ф.М. Достоевский) лежит онтологическая ошибка - незнание подлинной природы человека как тварного образа Божия, сложного телесно-душевно-духовного существа, поврежденного первородным грехом. «Совершенное правовое государство» или «коммунистическое общество» невозможны вовсе не потому, что человек фатально порочен и его невозможно перевоспитать соответствующим образом, но потому что и либеральная, и коммунистическая утопии изначально отвергли единственный способ такого перевоспитания-жизнь во Христе. А все остальные способы создания «совершенного человека» в конечном счете всегда ведут к прямо противоположному результату - но не из-за прагматических ошибок «преобразователей» (они по своей теории в целом действовали правильно), а потому, что таков онтологический закон человеческого бытия, не зная которого, люди хоронят себя в дебрях утопического сознания.

В свою очередь, не случайно, что когда последнее приобретает внешне респектабельную наукообразную форму, то в первую очередь оно начинает выполнять функции вовсе не науки, а «мировоззрения», жизненного credo, замещая собою абсолютные смысловые размерности человеческого сознания. Утопическое сознание, лежащее в основе всех секулярных идеологий, по своему происхождению является субститутом и псевдоморфозой сознания религиозного, вследствие чего всегда в той или иной степени возникает религиозное отношение и к названным идеологиям. Причем особенно остро в тех случаях, когда эти идеологии являются сознательно атеистическими - и это тоже не парадокс, а строгая закономерность.

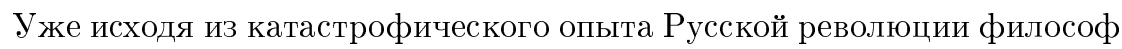
писал о квазирелигиозной и онтологически наивной природе революционного сознания (что относится не только к его тоталитарному, но и к либеральному варианту, который и начал революцию в России): «Предположение о возможности рационального устроения и упрощения жизни скрывает за собой и другое, еще далее и глубже идущее предположение: что зло и страдание могут быть побеждены разумом человеческим в совершенной общественности, что они связаны лишь с несовершенством учреждений и с неразумием отношений. Космологическую проблему зла и страдания здесь хотят решить в терминах социологических, зло мировое победить устроением социальных отношений. Но если борьба с общественным злом есть величайшая задача государственного строительства, то опыт всецелого и немедленного искоренения этого зла, представляя собою самообольщение человеческого ума, оказывается злом еще худшим, и приводит к бедствиям, еще более тяжким и невыносимым» ${ }^{9}$.

\footnotetext{
${ }^{9}$ Новгородцев П.И. О путях и задачах русской интеллигенции // Из глубины. Сбор-
} 
Таким образом, методом «от противного» становятся очевидны имманентные признаки принципиально неутопического общественного идеала, содержащегося в работах П.И.Новгородцева: 1) основанность на высших онтологических размерностях человеческого бытия, открывающихся только в религиозном опыте; 2) осознание принципиальной невозможности полной и окончательной реализации идеала в земном бытии, а тем самым, и его изначальной подчиненности конечной цели человеческого бытия - спасению души; 3) возможность и действительность реального воплощения идеала в любых, во всех без исключения общественных условиях - от первобытного состояния до «постмодерна», а тем самым и понимание большой условности понятий «прогресс» и «регресс», имеющих к общественному идеалу лишь опосредованное отношение; 4) иерархический характер общественного идеала - вторичность и производность его внешне-эмпирических параметров от внутренних духовно-нравственных оснований.

Для прояснения природы общественного идеала можно воспользоваться схемой Маркса, выделявшего три типа межчеловеческих отношений: «личную зависимость», «вещную зависимость» и «общение свободных индивидуальностей». Первая ошибка Маркса, порожденная его «религией прогресса», состояла в том, что он располагал эти типы стадиально как будто бы они последовательно сменяют друг друга. На самом же деле, они всегда сосуществуют на всех стадиях социальной эволюции но в разных «пропорциях» и соотношениях, причем, как правило, одни и те же люди одновременно пребывают во всех трех типах отношений между собой (это особенно наглядно в семейной жизни, но имеет место и во всех остальных сферах). Вторая ошибка, тоже порожденная религией «прогресса», состоит в представлении, будто бы последний тип отношений должен возникать и развиваться на более поздних стадиях, а достигать полного развития - якобы только на «коммунистической». В действительности происходит как раз обратное: в наибольшей степени «общение свободных индивидуальностей» было развито в традиционных обществах, а хуже всего - в техногенной урбанистической цивилизации, особенно на ее современной стадии. Причем попытки построения «коммунистического общества» искореняли «общение свободных индивидуальностей» ничуть не менее эффективно, чем все другие типы модернизации. Ослабление внешних форм зависимости индивида (уничтожение рабства, рост благосостояния и т.п.) само по себе не только не приводит к развитию «общения свободных индивидуальностей», но, как правило, наоборот, приводит к его деградации, поскольку это ослабление в первую очередь является средством утверждения индивидуализма. Стадиально на смену

ник статей о русской революции. - М.: Изд. МГУ, 1990. - С. 218-219. 
личной и вещной зависимостям в качестве новой доминанаты (но никогда не вытесняя их до конца) идет эго-зависимость - онтологически самая разрушительная разновидность рабства человека: $y$ своих собственных темных стихий, изнутри разрушающих личность.

Наиболее глубокое, интенсивное и содержательное «общение свободных индивидуальностей» имело место в традиционных обществах, основанных на религиозных ценностях - именно потому, что в последних людям в наибольшей степени есть о чем общаться. Человек традиционного религиозного общества живет в мире бесконечных смысловых размерностей, пронизывающих все детали и события как его личного, так и социально-исторического бытия, в «горизонте» бесконечной ответственности перед своим Творцом и всеми людъми; в перспективе Суда над всей своей жизнъю, каждым поступком и помыслом. Это состояние создает особый тип межчеловеческих отношений, при которых они, даже будучи глубоко укорененными в прагматику быта, оказываются центрированными на предельных ценностях, происходят перед Лицом «абсолютного Третьего» (М.Бахтин), вследствие чего даже мельчайшие детали бытовой и психической жизни человека обретают реально бесконечную смысловую глубину. Поэтому, избегая суесловия и общаясь преимущественно на бытовые темы, человек традиционной религиозной цивилизации de facto, то есть в более глубоком контексте, всегда говорит о своей жизни «пред Богом», и точно так же воспринимает сказанное другими. При всей жесткой регламентации жизни традиционными нормами, именно здесь человек в наивысшей степени является свободной индивидуальностью, поскольку человек абсолютно свободен и абсолютно индивидуален только в рамках Бого-человеческого отношения, ибо в рамках социальных и душевно-психических отношений оба названньх качества всегда относительны и ограничены по самой своей природе.

Говоря об «общественном идеале в свете бесконечности», русский философ в первую очередь и подразумевает тот факт, что общественная жизнь может быть помыслена в смысловом «горизонте» некоего «идеала» именно постольку, поскольку она мыслится как не равная самой себе, не сводимая только к социальным размерностям человеческого бытия. Если же общество в его наличном состоянии отрицается в рамках долженствования его инакового состояния, но которое при этом мыслится как всецело естественное, исключающее реализацию каких-либо сверхсоциальных, трансцендентных смыслов - тогда и возникает феномен уто$n u u$, который следует принципиально отличать от общественного идеала в строгом смысле слова, всегда включающего в себя реализацию именно таких смыслов и ценностей - святынь - как свой необходимый признак и критерий.

В конкретно-историческом смысле, как уже было показано выше, об- 
щественный идеал (в том строгом и философски корректном смысле слова, о котором говорит П.И. Новгородцев) в наибольшей степени реализуем в традиционной цивилизации, а среди всех видов последней - в христианской. Вместе с тем, нам хотелось бы обратить внимание на определенную сущностную структуру общественного идеала, которая непосредственно вытекает из ключевых формулировок П.И. Новгородцева, но осталась неэксплицированной у этого автора, в первую очередь потому что принадлежит к иной, философско-антропологической проблематике. Речь идет о диалогической природе общественного идеала, концептуализация которой составляет конечную цель настоящей статьи.

Новгородцев прямо указывает на диалогическую природу общественного идеала в следующих ключевых формулировках своего исследования: «Безусловная солидарность личности с общественной средой относится... к моменту бесконечной целости общения, т.е. к недостижимому и трансцендентному идеалу. Что же касается конкретных форм общественности, то в силу внутренней беспредельности личности они не способны ее удовлетворить» ${ }^{10}$. Ключевым понятием, фиксирующим сущностное «ядро» общественного идеала, здесь является «бесконечнал целость общения», недостижимая в земном бытии, но являюшаяся той исходной интенцией, реализация которой служит главным критерием степени воплощенности общественного идеала в конкретно-исторических условиях. Но это понятие вместе с тем является и универсальным определением диалога, в данном случае означая, что реальная внутренняя диалогичность социума является универсальной формой его причастности общественному идеалу.

Другое ключевое определение П.И. Новгородцева относится уже не к диалогичности как форме реализации идеала, но к сущностному определению самого диалога. Говоря о «заключительном результате, который дает внешнюю санкцию идеалу нравственного объединения всех», философ определяет его так: «Эта санкция есть вера в общечеловеческую истину и вселенскую правду. Если мы настаиваем на том, что этот отдаленный идеал есть истинное руководящее начало для каждого общества и для каждой эпохи, то именно потому, что мы верим в единство человечества, в единство общечеловеческой истины. Кто стоит на точке зрения относительности всех нравственных начал, для того нет почвы для безусловного общечеловеческого идеала» ${ }^{11}$.

Для большинства современных людей понятие «диалог» обычно ассоциируется как раз со «множеством точек зрения», «плюрализмом мнений», и, соответственно, со «множественностью истин». Такое понима-

${ }^{10}$ Новгородцев П.И. Об общественном идеале. - С. 200.

${ }^{11}$ Там же. - С. $136-137$. 
ние диалога и диалогичности хорошо сформулировано Б.А. Парахонским: «Диалог - это особая организация коммуникативных отношений, предполагающая равенство сторон в том, что касается осмысления фактов и оценки информации» ${ }^{12}$. П.И. Новгородцев же, напротив, полагает фундаментальным онтологическим основанием диалога как раз единство «общечеловеческой истины и вселенской правды» как «бесконечной целости общения» и «идеала нравственного объединения всех». Дело в том, что вопреки вышеупомянутым представлениям, сущность диалога всегда предполагает наличие «абсолютного Третьего»- онтологической причастности к общему Метасубъекту, общему смысловому пространству метатекста культуры и метаконтекста жизни, без чего диалогический процесс просто невозможен как таковой.

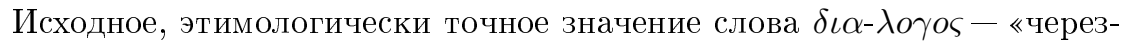
слово», «посредством слова»- несет в себе особый эвристический потенциал. Оно означает, что «диалог» первоначально мыслился не в контексте различения субгектов речи, а как раз наоборот-в контексте их глубинной общности в рамках единого, сверхсубъектного Слова, через и посредством которого только и возможно общение и взаимопонимание субъектов с разными жизненными мирами и разными коммуникативными установками. М.М.Бахтиным, как известно, это первичное значение понятия четко осознавалось и было концептуализировано в понятии «абсолютного третьего». Последнее, в свою очередь, может быть интерпретировано как наличие актуалъного метатекста, конституирующего пространство диалогического взаимодействия разных субъектных миров. «Абсолютный третий» является тем предельным смысловым горизонтом «меня» и любого «другого», благодаря наличию которого «я» $\mathrm{c}$ «другим» вообще конституируюсъ в качестве соотносимых субгектов. «В данном случае слово „третий“, - отмечает С.С.Гусев, - просто указывает на то обстоятельство, что коммуникативный процесс не сводится к структуре традиционной бинарной оппозиции, но требует явного указания на способ и средства объединения его крайних членов... Этот „третий собеседник“ является одинаково „внешним“ для всех... и поэтому обеспечивает возможность их связи» ${ }^{13}$. Разным содержательным уровням диалога соответствуют принципиально различные «третьи собеседники», но само их наличие остается инвариантным. Для типа, который условно может быть определен как тривиальный, таким «третьим» является непосредственный жизненный мир собеседников, зафиксированный в со-

\footnotetext{
12 Диалог и коммуникация - философские проблемы (Материалы «круглого стола») // Вопросы философии. - 1989. - №7. - С. 27.

${ }^{13}$ Гусев C.C. Самосознание и страх, диалог и Третий // Перспективы метафизики: Классическая и неклассическая метафизика на рубеже веков. - СПб.: Алетейя, 2000.C. 197-199.
} 
держаниях массового и группового сознания; для диалога в горизонте предельных, сакральных смыслов «третьим» становится Бог, являющий Свое Слово через Священное Писание и через непосредственный духовный опыт верующего. Естественно, граница между названными типами не является стеной, но наоборот, состоит из возможностей взаимоперехода. О сущностной укорененности подлинного межчеловеческого общения в «горизонте абсолютного» М. Бубер пишет так: «В непосредственное отношение к нам Бог вступает как абсолютная личность... Поэтому человеку, который поворачивается к Богу, нет нужды отворачиваться от всех других Я-Ты-отношений: правомочно он приносит все эти отношения Богу и дает им преобразиться «в лице Бога» ${ }^{14}$. Тем самым, концепция П.И. Новгородцева, апеллирующая к укоренености общественного идеала в Бого-человеческом отношении, к его производности от служения святыням - необходимо связана именно с этим, изначальным и более фундаментальным пониманием сущности диалога, прямо противоположным ходячим релятивистическим представлениям, доминирующим в мышлении современных гуманитариев.

В этом же контексте П.И.Новгородцев имеет основания говорить о принципиальной монологичности утопического сознания: «Утопия представляет собою мечту о всецелом устроении, а вместе с тем и упрощении жизни. Предполагается, что можно найти одно слово, одно средство, одно начало, имеющее некотрый всеобщий и всеисцеляющий смысл» ${ }^{15}$. На первый взгляд может показаться, что нет никакой разницы между верой в единство общечеловеческой Истины и поиском единого универсального «средства» решения всех проблем, предлагаемого утопиями. Однако, эта похожесть только кажущаяся, скрывающая за собой сущностную противоположность (эта кажимость во многом и объясняет соблазнительность утопий). Дело в том, что «одно средство», «одно начало» и т.д. утопий всегда есть плод индивидуалистического разума, имеющего цель изменить мир по своей волюнтаристической мерке, что всегда предполагает подавление оппонентов (иногда вплоть до их физического уничтожения). А общечеловеческая Истина, наоборот, по своей природе такова, что в принципе не может быть изобретением чьего-то индивидуального сознания, стремящегося к волюнтаристическому изменению общества. Приобщение к Истине всегда есть акт свободного выбора, опосредованный открытостъю Другому (в символическом смысле: другому сознанию, другому способу жизни, Богу как абсолютному Другому).

В силу этой необходимой опосредованности, приобщение к Истине $c y$ щностно диалогично (в отличие от навязчивых эмпирических «истин»

${ }^{14}$ Бубер М. Два образа веры.-М.: АСТ, 1999.-С. 121.

${ }^{15}$ Новгородцев П.И. О путях и задачах русской интеллигенции.-С. 218. 
объектного мира). Один из «секретов» утопии в том, что она имuтuрyem единство общечеловеческой Истины, выдавая за нее измышления чьего-то индивидуального и весьма испорченного ума. Другой ее «секрет» состоит в умении представить реалъные выражения общечеловеческой Истины в виде «пережитков деспотизма», «предрассудков» и «индивидуальных мнений». В обоих случаях утопия ловко использует «эффект Двойника» (А.А. Ухтомский), подменяющего диалог с подлинным лицом Другого, без чего движение к этой единой и единственной Истине невозможно.

О социально-политических формах и исторических результатах релятивистического понимания диалога П.И. Новгородцев писал в статьезавещании «Восстановление святынь» следующим образом: «при отсутствии абсолютных духовных основ все сводится к борьбе сил, к борьбе большинства и меньшинства... Качественные определения уступают место количественным ... Самое страшное и роковое в этом процессе - опустошение человеческой души. Путь автономной морали и демократической политики привел к разрушению в человеческой душе вечных связей и вековых святынь. Вот почему мы ставим теперь на место автономной морали теономную мораль и на место демократии, народовластия - агиократию, власть святынь. Не всеисцеляющие какие-либо формы спасут нас, а благодатное просвещение душ. Не превращение государственного строительства в чисто внешнее устроение человеческой жизни, а возвышение его до степени Божьего дела, как верили в это и как об этом говорили встарь великие строители земли Русской, вот что прежде всего нам необходимо» ${ }^{16}$.

Если перевести сказанное из понятий социальной философии в понятия философской антропологии, то эта мысль - о необходимости возращения от релятивистического к сущностному пониманию диалога. Естественно, в данном случае с нашей стороны это именно интерпретация, но она позволяет «вписать» наследие П.И. Новгородцева в одну из наиболее важных тенденций в философии XX века- возвращение от космоцентрической (античной по происхождению) парадигмы философствования к персонацентрической (библейской по своему генезису), которая наиболее ярко выражена в традициях «философии диалога» и религиозного экзистенциализма. Тем самым, есть основание говорить о значимости идей П.И.Новгородцева и для философской антропологии, а не только для социальной философии и философии права.

В качестве общих выводов анализа поставленной проблемы назовем следующие:

1. Понятие общественного идеала как таковое имеет важное эвристи-

\footnotetext{
${ }^{16}$ Новгородцев П.И. Восстановление святынь // Новгородцев П.И. Об общественном идеале. - М.: Пресса, 1991.-С. 579.
} 
ческое значение в силу своей связи с проблемой онтологии социального бытия и его «включенности» в экзистенциальное самоопределение человека в «горизонте» предельных ценностей и смыслов.

2. Важной заслугой работ П.И. Новгородцева является четкое обоснование сущностного критерия отличия общественного идеала от утопии, каковым является его укорененность в сфере религиозных ценностей, в отличие от квазирелигиозной веры в возможность «земного рая», свойственной утопиям всех типов.

3. «Бесконечная целость общения» как одно из ключевых содержательных определений общественного идеала в работах П.И.Новгородцева означает фундаментальность его диалогической природы, что, в свою очередь, позволяет рассматривать реальную внутреннюю диалогичность социальных отношений как имманентный критерий степени его устремленности к общественному идеалу.

4. Природа общественного идеала укоренена в диалоге в его первичном смысле - как причастности субъектов «абсолютному третьему» (М.Бахтин), их реальной устремленности к Абсолюту, вполне реализуемой лишь в рамках Бого-человеческих отношений, что, в свою очередь, означает и необходимую укорененность идеала в вере в единство общечеловеческой Истины.

Рассмотренные здесь аспекты теории общественного идеала требуют дальнейшей разработки в рамках проблематики философской антропологии. Религиозная основа общественного идеала (и его сущностная внутренняя диалогичность как антропологический аспект этой основы) составляют одну из концептуальных инвариант русской философской традиции, определяющих ее эвристическое значение для современности. 